present study two asymptomatic haemophiliacs who subsequently developed AIDS had antibodies to HTLV-III.

The observation that the proportion of asymptomatic haemophiliacs with antibodies to HTLV-III may have increased from 1983 to 1984 deserves further study using sequential samples from the same individuals. As the incubation period for the development of AIDS following blood transfusion has been estimated to range from 10 months to $4 \mathrm{yr}^{26}$, further studies are needed to evaluate the impact of this observation. Antibody positivity seems to be an indicator of viral infection in most healthy and leukaemic individuals who were naturally exposed to HTLV $-\mathrm{I}^{27-29}$ as well as in AIDS patients and healthy male homosexuals exposed to HTLV-III ${ }^{1-4}$. However, it is possible that a significant proportion of asymptomatic haemophiliacs might be exposed only to inactivated HTLV-III rather than to live virus, owing to the manufacturing process involved in the preparation of commercial factor VIII concentrate. In addition,

Received 30 August; accepted 26 September 1984.

1. Popovic, M., Sarngadharan, M. G., Read, E. \& Gallo, R. C. Science 224, 497-500 (1984).

2. Gallo, R. C. et af. Science 224, 500-503 (1984).

3. Schupbach, J. et al. Science 224, 503-505 (1984)

4. Sarngadharan, M. G., Popovic, M., Bruch, L., Schupbach, J. \& Gallo, R. C.Science 224, 506-508 (1984)

5. Francis, D. P., Curran, J. \& Essex, M. J. int. Cancer Inst. 71, 1-4 (1983).

6. Davis, K. C., Horsburgh, C. R., Jr, Hasibu, U., Schocket, A. L. \& Kirkpatrick, C. H. Ann. intern. Med. $98,284-286$ (1983)

7. Elliott, J. L. et al Ann intern. Med. 98, 290-293 (1983).

8. Homma, T. et al. Science 225, 716-718 (1984)

9. Essex, M. et al. Science 221, $1061-1064$ (1983).

10. Lee, T. H. et al. Proc. natm. Acad. Sci. U.S.A. 81, 3856-3860 (1984)

11. Essex, M. et al. Science 220, 859-862 (1983).

12. Gelmann, E. P. et al. Science 220, 862-865 (1983)

13. Gallo, R. C. et al Science $220,865-867$ (1983)

14. Barre-Sinoussi, F et al Science 220, 868-871 (1983).

15. Jaffe, H. W. et al. Science 223, 1309-1312 (1984). it is clear that those individuals exposed to factor IX preparations are also at risk for the development of antibodies to HTLV-III. Further studies are needed to determine whether the presence of antibodies to HTLV-III indicates immunization, infection or an asymptomatic carrier state. In addition, the relationship between HTLV-III seropositivity and immunological dysfunction, which has been shown to be widespread among apparently healthy haemophiliacs ${ }^{30,31}$, requires investigation.

We thank Dr R. C. Gallo for the reference cell cultures and the reference antisera. This research was supported by National Research Service Award ST 32CA9382 (L.W.K.), Association pour le Développement de la Recherche sur le Cancer, Fondation pour la Recherche Médicale, and Philippe Foundation (F.B.), NIH grants AI21161 (J.L.S.) and CA37466 and CA18216 (M.E.). J.L.S. is an established investigator of the American Heart Association.

16. Feorino, P. M. et al. Science 225, 69-72 (1984).

17. Kalyanarman, V. S. et al Science 225, 321-323 (1984).

18. Essex, M. Hardy, W. D., Jr, Cotter, S. M., Jakowski, R. M. \& Stiski, A. Infect. Immun $11,470-475$ (1975)

19. Kreiss, J. K. et at. Ann intern. Med. 100, 178-182 (1984)

20. Cheeseman, S. H., Sullivan, J. L., Brettler, D. B. \& Levine, P. H. J. Am. med. Ass. 252, $83-85$ (1984).

21. Evatt, B. L. et al Lancet it, 698-701 (1983).

22. Lee, T. H. et al. Proc. natn. Acad. Sci. U.S.A. (in the press).

23. Miyoshi, I. et al. Lancet i, 683-684 (1982).

24. Saxinger, W. C. \& Gallo, R. C. Lancet 1, 1074 (1982)

25. Okochi, K. Sato, H. \& Hinuma, Y. Vox Sang 46, 245-253 (1984).

26. Curran, J. W. et al. New Engl. J. Med. 310, 69-75 (1984).

27. Kalyanaraman, V. S. et al. Proc. natn. Acad. Sci. U.S.A. 79, 1653-1657 (1982)

28. Gotoh, Y. 1., Sugamura, K. \& Hinuma, Y. Proc. natn. Acad. Sci. U.S.A. 79, 4780-4782 (1982)

29. Robert-Guroff, M. et al. Science 215, 975-978 (1982).

30. Lederman, M. M., Ratnoff, O. D., Scillian, J. J., Jones, P. K. \& Schacter, B. New Eng. $J$ Med. 308, 79-82 (1983).

31. Menitrove, J. E. et al. New Engl. J. Med. 308, 83-86 (1983).

\section{Significance of herpesvirus immediate early gene expression in cellular immunity to cytomegalovirus infection}

\section{Matthias J. Reddehase \& Ulrich H. Koszinowski}

Federal Research Centre for Virus Diseases of Animals, Tübingen, PO Box 1149, D-7400 Tübingen 1, FRG

Interstitial pneumonia linked with reactivation of latent human cytomegalovirus due to iatrogenic immunosuppression can be a serious complication of bone marrow transplantation therapy of aplastic anaemia and acute leukaemia ${ }^{1}$. Cellular immunity plays a critical role in the immune surveillance of inapparent cytomegalovirus infections in man and the mouse ${ }^{1-7}$. The molecular basis of latency, however, and the interaction between latently or recurrently infected cells and the immune system of the host are poorly understood. We have detected a so far unknown antigen in the mouse model. This antigen is found in infected cells in association with the expression of the herpesvirus 'immediate early' genes and is recognized by cytolytic T lymphocytes (CTL) ${ }^{8}$. We now demonstrate that an unexpectedly high proportion of the CTL precursors generated in vivo during acute murine cytomegalovirus infection are specific for cells that selectively synthesize immediate early proteins, indicating an immunodominant role of viral nonstructural proteins.

According to the static state hypothesis of latency ${ }^{9}$, it is assumed that viral progeny are not produced because the transcription process of the virus is interrupted reversibly at an early stage in the cycle of virus multiplication. In herpes virus infections of permissive cells in vitro, analysed in detail for herpes simplex viruses ${ }^{10,11}$, viral protein synthesis is coordinately regulated and starts with the expression of the 'immediate early' (IE) genes, which are transcribed by host RNA polymerase II. The IE proteins exert important control functions as exemplified by their ability to act as transcriptional activators ${ }^{12,13}$ and they need to be present throughout the replication cycle of herpes-
Table 1 Determination of the IL-CTLp frequency by LDCC

$\begin{array}{ccccc}\begin{array}{c}\text { Dose of lectin } \\ \left(\mu \mathrm{ml}^{-1}\right)\end{array} & \begin{array}{c}\text { IL-CTLp } \\ \text { frequency }\end{array} & \begin{array}{c}\text { No. of IL-CTLp } \\ \text { per } 10^{6} \text { lymphocytes } \\ (95 \% \text { confidence limits })\end{array} & \text { pMC* } \\ \text { Con A } & 5 & 1 / 5,900 & 171(126-215) & 0.23 \\ & 10 & 1 / 2,800 & 359(217-502) & 0.11 \\ & 20 & 1 / 2,600 & 383(270-495) & 0.50 \\ \text { PHA } & 5 & 1 / 5,600 & 179(124-234) & 0.24 \\ & 10 & 1 / 9,500 & 105(71-140) & 0.52 \\ & 20 & 1 / 7,600 & 132(93-171) & 0.24\end{array}$

BALB/c $\left(H-2^{d}\right.$ haplotype $)$ mice were infected at the left hind footpad with $10^{5}$ PFU of tissue-culture propagated MCMV (ATCC VR-194 Smith strain) and 8 days later lymphocytes derived from the draining popliteal lymph nodes were tested for the frequency of activated CTLp in a limiting dilution assay ${ }^{20}$. In brief, graded numbers of lymphocytes were cultivated for 6 days in 96-well round-bottomed microtitre plates with no addition of viral antigen using medium MEM- $\alpha$ (Gibco) supplemented with $10 \%$ vol. fetal calf serum and $20 \%$ vol. interleukin-2 containing supernatant. Starting the dilution series with $1 \times 10^{5} \mathrm{lym}$ phocytes, $7 \log _{2}$ dilution steps were performed with 24 replicate microcultures each. To detect all CTL clones irrespective of their antigenspecificity, the LDCC assay was applied. Various doses of the lectins Con A (Pharmacia) or PHA (Flow Laboratories) were added to $10^{3}$ ${ }^{51} \mathrm{Cr}$-labelled, noninfected MEF and CTL at the beginning of a standard 3- $\mathrm{h}{ }^{51} \mathrm{Cr}$ release assay. Precursor frequencies were estimated from the proportion of nonresponding microcultures using the minimum $x^{2}$ $(\mathrm{MC})^{32}$ and maximum likelihood $(\mathrm{ML})^{33}$ methods. Only the results of the MC evaluation are shown.

* Probability calculated by MC method. According to the proposition of Taswell ${ }^{32}$ an estimate was accepted for a probability of $\boldsymbol{P}>0.05$ and a $\mathrm{ML}-\mathrm{MC}$ deviation of $<10 \%$.

viruses to permit transcription of the 'early' and 'late' genes ${ }^{14}$. Interference with viral transcription at the stage of the expression of IE genes may be involved in establishing viral latency; hence many efforts have been made to clone and map the IE regions of herpesvirus genomes, including those of human ${ }^{15,16}$ and murine cytomegalovirus (MCMV) ${ }^{17-19}$. In particular, reexpression of IE genes must be one of the first events in virus reactivation from latency. Selective synthesis of IE proteins leads 


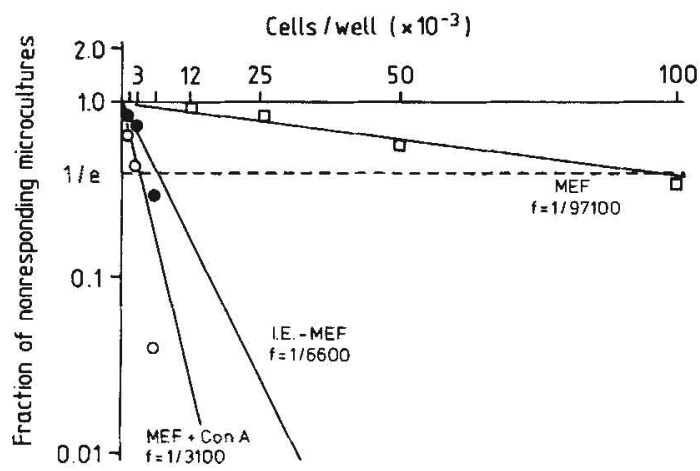

Fig. 1 High frequency of LYDIEA-specific IL-CTLp. CTL were generated by in vitro interleukin-mediated expansion of in vivo activated interleukin-receptive CTLp (IL-CTLp) as outlined in Table 1. Second-passage mouse embryo fibroblasts (MEF) were used as a source of target cells for the ${ }^{51} \mathrm{Cr}$-release assay. To determine the negative or positive reference frequencies, noninfected MEF were used either in the absence of lectin or with addition of $20 \mu \mathrm{g} \mathrm{ml}^{-1}$ Con A, respectively. Infected target cells after selective expression of immediate early genes (IE-MEF) served to determine the frequency of IL-CTLp specific for the immediate early antigen (LYDIEA) of MCMV. Details of the limiting dilution assay are given in Table 1 and details of the target cell preparation in Table 2.

to the expression of an antigen on the cell surface ${ }^{8}$. This antigen is recognized by CTL and was therefore designated lymphocytedetected IE antigen (LYDIEA). LYDIEA-specific CTL represented a distinct subset, separate from those CTL recognizing viral structural antigens ${ }^{8}$. The mere fact, however, that during MCMV infection LYDIEA-specific CTL are generated did not allow definite conclusions about the relative significance of the immune response to LYDIEA in comparison with the response to other antigens specified by MCMV.

The solution of two experimental problems was a prerequisite for attempts to evaluate the significance of LYDIEA. First, in vivo primed CTL precursors (CTLp) can be detected only after clonal expansion in vitro by testing their cytolytically active progeny. This expansion has to be performed in the absence of antigen because restimulation in vitro may favour or disfavour the growth of CTLp specific for certain antigens and thereby cause a distortion of the numerical in vivo representation of specificities. The expansion of interleukin-receptive CTLp (IL-
CTLp) by interleukin solves this problem as that procedure selects cells only on the basis of differentiation ${ }^{20}$.

The second problem arises from the fact that progeny CTL are usually detected by their ability to recognize target cells carrying the relevant antigens. This recognition requires sufficient amounts of antigen to be present at the cell membrane ${ }^{21}$. Selective and sufficient expression of LYDIEA can be achieved ${ }^{8}$, but it is not certain in a particular experiment whether each of the other viral antigens is also expressed sufficiently. Therefore, to detect all IL-CTLp generated during MCMV infection regardless of their antigen-specificity, the lectin-dependent cellular cytotoxicity (LDCC) assay was applied. In this assay the T-cell mitogenic lectins concanavalin $A$ (Con A) and phytohaemagglutinin (PHA) are used to bypass the requirement for specific interaction between CTL and target cells ${ }^{22,23}$. The highest frequency of IL-CTLp was measured when ConA was added at doses of $10-20 \mu \mathrm{g} \mathrm{ml}^{-1}$ (Table 1). The fact that the corresponding frequency in unprimed mice ranged from 1 in 70,400 to 1 in 91,400 lymphocytes (data not shown) proved that the CTL detected in the lectin-dependent cellular cytotoxicity (LDCC) assay were derived from in vivo sensitized precursors. This condition was then used to assess the total frequency of IL-CTLp.

The results of a representative limiting dilution assay are shown in Fig. 1 and those of an independent second experiment summarized in Table 2. The frequency of LYDIEA-specific IL-CTLp present in a draining popliteal lymph node was found to be 1 in 6,600 lymphocytes (Fig. 1) or 1 in 6,900 lymphocytes, respectively (Table 2 ). This determination was carried out on target cells that selectively expressed high amounts of IE proteins. The selective transcription of IE genes in target cells was achieved by infection in the presence of the translation inhibitor cycloheximide that led to an accumulation of IE RNA. The subsequent release from cycloheximide and further cultivation in the presence of the transcription inhibitor actinomycin $D$ then resulted in an enhanced synthesis of IE proteins and simultaneously prevented further viral transcription ${ }^{8,19}$.

During noninterrupted (productive) infection, the synthesis of IE proteins is followed by the synthesis of so-called early proteins and, after viral DNA replication, of late proteins which include the major viral structural proteins ${ }^{10,24}$. Among those especially the glycoproteins of the virion envelope should contribute significantly to the antigenicity of infected cells. Nevertheless, when tested on cells corresponding to the late

Table 2 IL-CTLp frequencies as determined by antigen-specific or lectin-dependent cellular cytotoxicity

\begin{tabular}{|c|c|c|c|}
\hline Target cell (virus dose; inhibitors) & IL-CTLp frequency & $\begin{array}{c}\text { No. of IL-CTLp } \\
\text { per } 10^{6} \text { lymphocytes } \\
(95 \% \text { confidence limits })\end{array}$ & $\mathrm{pMC}$ \\
\hline $\begin{array}{l}\operatorname{MEF}(-; \mathrm{CH} \text {-Act.D }) \\
\operatorname{MEF}+\mathrm{Con} \mathrm{A}(-; \mathrm{CH} \text {-Act.D) }\end{array}$ & $\begin{array}{l}1 / 166,400 \\
1 / 2,700\end{array}$ & $\begin{array}{c}6(4-8) \\
371(226-516)\end{array}$ & $\begin{array}{l}0.35 \\
0.27\end{array}$ \\
\hline $\begin{array}{l}\text { IE-MEF }(0.05 ; \text { CH-Act.D }) \\
\text { Late-MEF }(0.05 ; \text {-Act.D) }\end{array}$ & $\begin{array}{l}1 / 6,900 \\
1 / 11,300\end{array}$ & $\begin{array}{r}146(97-195) \\
89(60-118)\end{array}$ & $\begin{array}{l}0.16 \\
0.24\end{array}$ \\
\hline $\begin{array}{l}\text { UV-MCMV-MEF }(0.05 ; \mathrm{CH}-A c t . D) \\
\text { UV-MCMV-MEF }(0.5 ; \mathrm{CH}-A c t . D) \\
\text { UV-MCMV-MEF }(5 ; \text { CH-Act.D })\end{array}$ & $\begin{array}{l}1 / 85,300 \\
1 / 44,300 \\
1 / 14,900\end{array}$ & $\begin{array}{l}12(8-16) \\
23(12-33) \\
67(48-86)\end{array}$ & $\begin{array}{l}0.35 \\
0.16 \\
0.08\end{array}$ \\
\hline
\end{tabular}

Second-passage MEF were used as target cells throughout. Infection was performed under centrifugal enhancement conditions ${ }^{34}$ ( $800 \mathrm{~g}$ for 30 min) with the indicated virus dose of infection that is given in plaque-forming units (PFU) per cell as determined in a conventional plaque titration assay. The centrifugation enhances the efficiency of infection by 20 - to 80 -fold and thus a virus dose of 0.05 PFU corresponds with an effective multiplicity of about 1-4 PFU per cell. At a multiplicity of 100-400 PFU per cell target cells started to disintegrate and therefore the application of higher doses was preciuded. For the preparation of IE targets and the appropriate controls, infection and $3 \mathrm{~h}$ of cultivation were performed in the presence of cycl6heximide $\left(\mathrm{CH}, 50 \mu \mathrm{g} \mathrm{ml}^{-1}\right)$. Thereafter, $\mathrm{CH}$ was washed out and actinomycin D (Act.D, $\left.5 \mu \mathrm{g} \mathrm{ml} l^{-1}\right)$ was added. Only for the preparation of the late-MEF target, infection was carried out in the absence of $\mathrm{CH}$ and viral replication was allowed to proceed for $20 \mathrm{~h}$ until transcription was stopped by addition of actinomycin D. To test lectin-dependent cytotoxicity, Con $\mathrm{A}$ was added during the effector phase at a

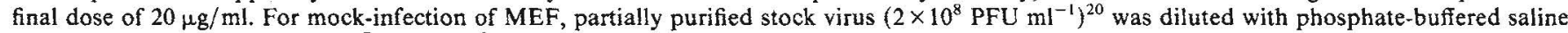
to a final concentration of $1 \times 10^{7} \mathrm{PFU} \mathrm{m} \mathrm{m}^{-1}$ and then exposed as an $1-\mathrm{mm}$ layer to a 10 -min irradiation with a $90 \mathrm{~W}$ UV-illuminator at $254 \mathrm{~nm}$. The distance between specimen surface and ultraviolet-screen was adjusted to give an intensity of $30 \mathrm{~J} \mathrm{~m}^{-2} \mathrm{~s}^{-1}$. To control the effect of irradiation on viral protein synthesis ${ }^{35}$, MEF were infected with the highest dose of virus used in the experiments (5 PFU equivalents per cell) and IE protein synthesis was enhanced by inhibitor treatment. Monoclonal antibody 6/58/1 (to be described elsewhere) was then used to detect IE nuclear antigen by indirect immunofluorescence. Irradiation of virus for $2.5 \mathrm{~min}\left(4,500 \mathrm{~J} \mathrm{~m}^{-2}\right)$ reduced the number of $1 E$ antigen positive cells to less than $1 \%$ and after $5 \mathrm{~min}$ of irradiation viral protein synthesis was abolished in all cells. 
stage of viral replication, the frequency of IL-CTLp was only 1 in 12,800 lymphocytes (not depicted in Fig. 1) or 1 in 11,300 lymphocytes, respectively (Table 2 ).

In addition to de novo synthesized antigens, virion proteins or glycoproteins inserted into the cell membrane during the process of penetration can directly account for an antigenicity of MCMV-infected cells. This has been demonstrated previously by infection of cells in the continuous presence of actinomycin D or cycloheximide ${ }^{8}$. Different treatment, mock-infection with UV-inactivated virus, still permits the synthesis of cellular proteins which might be induced by viral structural proteins and could also contribute to target formation. This control is therefore indicated to discriminate between target antigens induced by the IE activity of the viral genome and those antigens whose expression does not require IE protein synthesis. When mockinfection of targets was performed with a dose of ultravioletinactivated virus equivalent to the dose of infectious virus applied for preparing the IE target, the frequency was only 1 IL-CTLp in 85,300 lymphocytes (Table 2). This result proved that the high frequency of 1 IL-CTLp in 6,900 lymphocytes, detected with the IE target, was indeed due to the expression of an IE antigen and thus referred to LYDIEA-specific IL-CTLp. This conclusion is further confirmed by the finding that in the absence of viral genome-induced protein synthesis even a hundred-fold increase in the virus dose did not allow to detect the number of IL-CTLp that could be detected with the IE target or with the productively infected target (Table 2 ).

The total frequency of IL-CTLp in these experiments was found to be 1 in 3,100 lymphocytes (Fig. 1) or 1 in 2,700 lymphocytes, respectively (Table 2 ). Hence, based on the determination of the total IL-CTLp frequency, the LYDIEA-specific subset comprised $40-50 \%$ of all IL-CTLp generated during infection.

The finding that such a substantial proportion of the IL-CTLp recognize an antigen expressed during the IE phase of viral replication was unexpected because transcription at that stage is restricted to only few genes, while extensive transcription from the whole genome occurs at later stages ${ }^{19}$.

Three possibilities might explain the high frequency of LYDIEA-specific IL-CTLp: First, the primary $T$ cell specificity repertoire of $\mathrm{BALB} / \mathrm{c}$ mice may already contain a high relative number of precursors specific for this antigen. There is no approach to test this possibility as limiting dilution experiments have revealed an extremely low frequency of primary CTLp specific for $\mathrm{MCMV}^{20}$ or herpes simplex virus ${ }^{25}$ and that is why a reliable comparison between particular antigens is not feasible.

Second, the expression of antigens may be different in the tissues of the infected animal than predicted from the productive infection of embryonic fibroblasts in vitro. Since in the immunocompetent host MCMV does not replicate at the site of intraplantar infection, whereas after immunosuppression fibroblasts of the footpad tissue are productively infected (manuscript in preparation), the immune system is involved in terminating the in vivo viral replication at an early stage. This could imply a preferential sensitization of LYDIEA-specific CTLp and explain the high proportion of LYDIEA-specific IL-CTLp in the draining lymph node. We are now testing the amount of IE gene expression by in situ hybridization using cloned viral DNA fragments ${ }^{19}$.

Third, the IE antigen may be highly immunogenic. Its molecular identity has first to be defined in order to evaluate this alternative. At present it is known that the expression of LYDIEA requires transcription and translation ${ }^{8}$ and coincides with the synthesis of a phosphorylated but not glycosylated protein of 89,000 apparent relative molecular mass. This protein and its post-translational modification products are the dominant IE proteins located in the nucleus and cytoplasm of the infected cell (G. M. Keil et al., in preparation). Since recognition by CTL must be considered as a prima facie evidence for surface localization of an antigen, the actual relationship between these serologically detectable intracellular proteins and the antigen LYDIEA requires further analysis. The presence of nonglycosylated viral proteins, located predominantly in the nucleus and cytoplasm, coincides with the recognition of infected cells by CTL also in other virus infections such as EpsteinBarr virus ${ }^{26}$, simian virus $40^{27,28}$ and influenza virus ${ }^{29-31}$. In this context it has been suggested that processed products rather than the intact protein may represent the actual antigen ${ }^{31}$ or that the intracellular protein may modify other viral or cellular products $^{29}$.

Irrespective of the so far unknown molecular identity of LYDIEA, the requirement of IE proteins for the synthesis of viral structural proteins during acute infection or after reactivation from latency raises the possibility of a physiological role of LYDIEA-specific CTL in the surveillance of viral latency. LYDIEA-specific memory-CTL which are present in latently infected mice ${ }^{8}$ could be activated as soon as IE genes are expressed and eliminate recurrently infected cells before the assembly of progeny virions.

This work was supported by two grants to U.H.K. of the Deutsche Forschungsgemeinschaft, SFB 120 and Ko 571/8. We thank Ms A. Lüske for technical assistance.

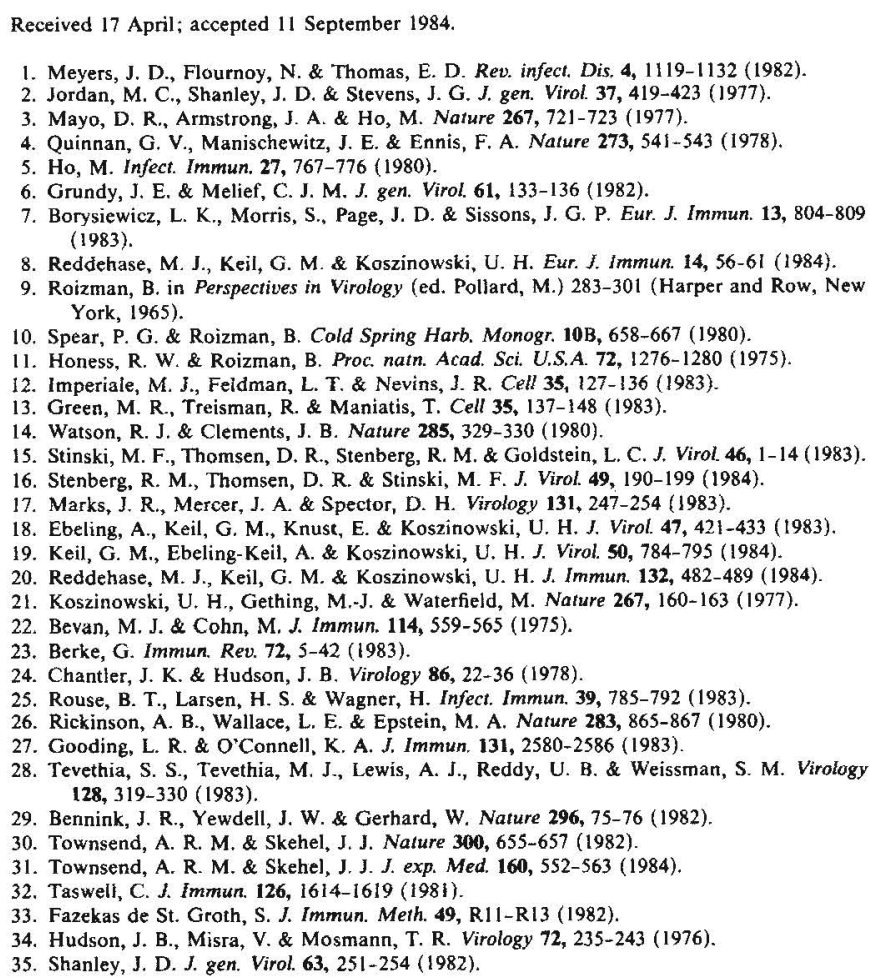

\section{Phorbol ester and diacylglycerol mimic growth factors in raising cytoplasmic $p H$}

\section{W. H. Moolenaar, L. G. J. Tertoolen \& S. W. de Laat}

Hubrecht Laboratory, International Embryological Institute, Uppsalalaan 8, 3584 CT Utrecht, The Netherlands

There is now good evidence that cytoplasmic $p H\left(p H_{i}\right)$ may have an important role in the metabolic activation of quiescent cells ${ }^{1,2}$. In particular, growth stimulation of mammalian fibroblasts leads to a rapid increase in $\mathrm{pH}_{\mathrm{i}}\left(\right.$ refs 3-6), due to activation of a Na${ }^{+} / \mathrm{H}^{+}$ exchanger in the plasma membrane ${ }^{4}$, and this alkalinization is necessary for the initiation of DNA synthesis? ${ }^{7}$. However, the mechanism by which mitogens activate the $\mathrm{Na}^{+} / \mathrm{H}^{+}$exchanger to raise $p H_{i}$ is not known, although an increase in cytoplasmic free $\mathrm{Ca}^{2+}\left(\left[\mathrm{Ca}^{2+}\right]_{i}\right)$ has been postulated as the primary trigger ${ }^{8-10}$. We 